\title{
Enfoque ortodóncico en el tratamiento multidisciplinario de pacientes adultos. Su relación con la periodoncia
}

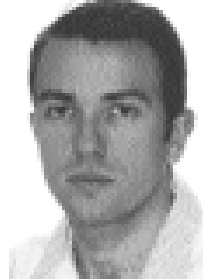

Sada-G arralda, Vicente

\section{An orthodontic approach in the multidisciplinary treatment of adult patients.}

\author{
Its relation with periodontics
}

\section{Sada- Garralda, Vicente * Caffesse, Raúl G.**}

*Master en Ortodoncia, Universidad Intercontinental, México, DF. Práctica privada dedicada en exclusiva a la ortodoncia en Navarra. **Profesor del Postgrado de Periodoncia Universidad Autónoma de Nuevo León, Monterrey, México.
Resumen: la presente comunicación, trata de enfatizar la estrecha relación que en el tratamiento multidisciplinario de pacientes adultos, deben tener las materias de ortodoncia y periodoncia. Bajo ningún aspecto, esta publicación considera incluir todos y cada uno de los aspectos en que se debe basar esa relación. Muchos de ellos serán objeto de presentaciones futuras.

El objetivo es poner de manifiesto, algunas de las áreas en que esa estrecha relación puede beneficiar el tratamiento de pacientes con problemas complejos. Es evidente, que en el momento actual no se puede considerar más al tratamiento ortodóncico, como limitado a niños y jóvenes. El conocimiento ganado en biología ósea y la respuesta de los tejidos a fuerzas ligeras, así como en la etiología y prevención de los problemas periodontales, permite hoy en día incorporar la ortodoncia al tratamiento de pacientes adultos. Esto es posible independientemente de su edad y su compromiso periodontal, siempre y cuando se pueda restaurar y mantener la salud de los tejidos periodontales. Logrando la colaboración, el entendimiento y la coordinación de las diferentes especialidades en el tratamiento conjunto del paciente, se podrán solucionar de manera mucho más satisfactoria, los múltiples problemas que los pacientes suelen presentar. Así se logrará el objetivo final de la odontología que es restaurar forma, función y estética de manera prolongada.

Palabras clave: Tratamiento multidisciplinario, Pacientes adultos, Ortodoncia, Periodoncia.

Abstract: This communication emphasizes the close relationships that periodontics and orthodontics must maintain during the multidisciplinary treatment of the adult patient. Under no consideration this publication is intended to include all and each of the aspects that should be considered in this close relationship. Many of those aspects will be discussed in future articles.

The objective has been to outline and highlight some of the areas in which this cooperation could benefit the treatment of patients with complex problems to be solved. It is evident that at the present it is not possible to continue considering orthodontic treatment as limited to children and adolescents. The knowledge gained in bone biology and tissue response to light forces, as well as in the etiology and prevention of periodontal problems, give the basis for the incorporation of orthodontics to the treatment of adult patients. This is possible independently of their age and periodontal involvement, if periodontal health can be achieved and maintained. If the cooperation, understanding and coordination of the different specialties can be achieved during the joint treatment of the patient, the multiple problems that these patients could present could be solved in a much more satisfactory manner. In this fashion it will be possible to achieve the final objective of modern dentistry that is to restore form, function and esthetics for many years.

Key words: Multidisciplinary treatment, Adult patients, Orthodontics, Periodontics.

\begin{tabular}{ccc}
\hline Fecha recepción & Fecha última revisión & Fecha aceptación \\
$26-05-2003$ & $26-09-2003$ & $07-10-2003$ \\
\hline
\end{tabular}

BIBUD [1138-123X (2003)8:6; noviembre-diciembre 593-724]

Sada-Garralda V, Caffesse RG. Enfoque ortodóncico en el tratamiento multidisciplinario de pacientes adultos. Su relación con la periodoncia. RCOE 2003;8(6):723-784. 


\section{Introducción}

La filosofía del tratamiento ortodóncico ha cambiado significativamente en las últimas décadas. Mientras era la norma tratar maloclusiones en niños, hoy es cada día mayor la cantidad de pacientes adultos que acuden a la consulta solicitando ser tratados ortodóncicamente.

Ya no se trata de cómo modificar el crecimiento o qué aparatos poner para conseguir una buena clase I canina pues se conocen varias filosofías que por diferentes caminos, pueden llegar a un resultado que satisface los requerimientos funcionales y estéticos que todo tratamiento ortodóncico debe cumplir.

Los problemas vienen al tratar bocas con muchas pérdidas dentales y con enfermedad periodontal que limitan a la hora de hacer movimientos y que hacen plantear una solución más conservadora. Normalmente estos pacientes han tenido malas experiencias anteriormente y desconfían si se les plantea una solución con más extracciones de las que ya se les han hecho. Además, son pacientes que requieren aparatología especial debido a sus compromisos estéticos.

Todo esto obliga a colaborar con otros especialistas para poder llevar a cabo un tratamiento adecuado. Pueden existir puntos de vista diferentes que hay que solucionar antes de comenzar. L ideal sería trabajar en el mismo consultorio, para planear y realizar ciertos procedimientos conjuntamente. Muchas veces esto es imposible, resultando difícil tener una buena comunicación y coordinación

La odontología nos permite hoy ofrecer soluciones que antes parecían lejanas o imposibles. Nótese como ejemplo los adelantos en el campo de la periodoncia y endodoncia y la incorporación de implantes osteointegrados a la terapia corriente. Estos permiten rehabilitaciones extensas en áreas desdentadas, como también obtener anclaje para los movimientos ${ }^{1}$.

Del mismo modo, el acercamiento entre la ortodoncia y la cirugía ortognática, es un ejemplo que ha permitido alcanzar resultados espectaculares en el tratamiento de malas relaciones intermaxilares en el paciente adulto.

Todas las especialidades dentro de la odontología, están avanzando para poder salvar dientes que antes se perdían. La ortodoncia debe de seguir la misma línea y ofrecer nuevas posibilidades, no sólo tratando casos en adultos que son cada vez más complejos, sino preferiblemente procurando tratarlos sin extracciones. Así, valorando el estado periodontal, la forma de los dientes y la cantidad de esmalte que estos tienen, se podrá recurrir al remodelado interproximal para tratar sin extracciones casos de mayor apiñamiento ${ }^{2}$.

La ortodoncia debe también proveer al paciente adulto de técnicas de tratamiento que no afecten su estética, como por ejemplo, la aparatología lingual. Más de 20 años han sido necesarios para evolucionar su mecánica lo suficiente como para afrontar un tratamiento con total seguridad ${ }^{3-5}$.

Sigue siendo más complicada que la técnica vestibular, pero si se recibe un adecuado entrenamiento y se prepara cada caso con mucha precisión, es bastante predecible e incluso se pueden conseguir resultados más rápidos, pues los brackets están más cerca del centro de resistencia de los dientes.

El objeto de esta serie de publica- ciones será el de presentar en forma coordinada, todas estas técnicas y enfoques terapéuticos, con el fin de solucionar los problemas clínicos a ser tratados en el paciente adulto por muy complicados que sean.

\section{Como coordinar los tratamientos de}

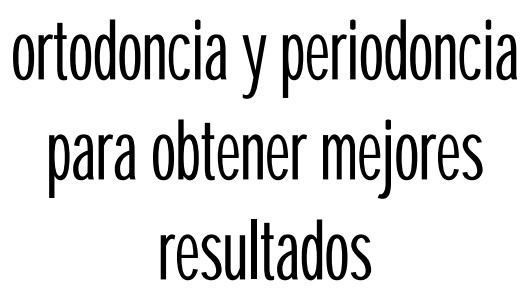

Normalmente casi todos los pacientes adultos tienen una problemática muy similar. Les faltan dientes y los que les quedan se han movido hacia las zonas desdentadas. Se han cerrado los espacios dificultando la restauración protésica, ya que no caben las coronas o en otras ocasiones el espacio es muy grande. Muy pocas veces hay una buena oclusión y las fuerzas producidas por los músculos de la masticación sobrecargan más unos dientes que otros y se suele producir una pérdida de la dimensión vertical. Es, por lo tanto, necesario hacer tratamiento ortodóncico en un alto porcentaje de ellos.

Además, han llegado hasta esta situación porque no han tenido un seguimiento correcto y tampoco tienen en gran parte de los casos unos correctos hábitos de higiene a pesar de que se cepillen los dientes todos los días. Es común que presenten también enfermedad periodontal en mayor o menor medida. Como se ve, 
casi todos necesitan tratamiento ortodóncico y periodontal, así que hay que estar muy bien coordinados, si se quiere conseguir el mejor resultado.

\section{Premisas periodontales}

Todos los casos que necesitan tratamiento multidisciplinario, deben empezar con un diagnóstico periodontal. Es importante que el dentista sepa diagnosticar correctamente un problema periodontal en sus fases iniciales y no dejar que evolucione hasta fases en las que se ve a simple vista y que tiene efectos irreversibles. Los ortodoncistas, como profesionales expertos, también deben seguir estas pautas.

Después de hacer esta evaluación mediante sondaje, radiografías, modelos de estudio y fotografías, se determinará si necesita o no tratamiento periodontal. En caso de necesitarse, siempre debe hacerse antes que el ortodóncico ya que de lo contrario se agravaría el problema periodontal. Nunca se debe mover un diente con enfermedad periodontal sin antes tratarlo y que deje de sangrar al sondaje. Es importante subrayar que más que la profundidad de la bolsa o la pérdida de hueso, debemos fijarnos en el sangrado pues es el signo que más evidencia la actividad de la lesión. Convertir una lesión activa en inactiva, es el objetivo principal del tratamiento periodontal y hay que hacerlo de la manera más conservadora posible. Obtener un epitelio de unión largo, es mejor que eliminar por completo la bolsa pues va a ser mucho más estético al final del tratamiento ${ }^{6}$.

Cuando se ejerce una fuerza sobre un diente, se produce una presión en el ligamento periodontal que supone una disminución del aporte sanguíneo ${ }^{7}$. Si se hace sobre un tejido sano, no supone ninguna pérdida de ligamento y por lo tanto se puede hacer tratamiento ortodóncico en cualquier paciente con enfermedad periodontal, no importando cuanto soporte tenga, siempre que la inflamación esté controlada ${ }^{8,9}$. Esto no quiere decir que se deba hacer todo el tratamiento periodontal antes, ya que hay ciertos procedimientos que es preferible postergarlos hasta después de la ortodoncia ${ }^{10}$.

En resumen, es necesario enfatizar que primero se trata la inflamación con los procedimientos que sean necesarios, incluidas las cirugías de acceso para poder limpiar mejor. Después debe hacerse el tratamiento ortodóncico y por último, cualquier cirugía de regeneración ósea o estética. El primer caso clínico presentado demuestra esta secuencia (fig. 1).

Caso clínico 1. Paciente de sexo masculino de 36 años, fumador, con periodontitis crónica avanzada. En el examen clínico demostraba pérdida de soporte con inflamación gingival generalizada y maloclusión severa. Se presentaban bolsas de $6-9 \mathrm{~mm}$ afectando todo el sector antero superior con movilidad de los dientes. El canino superior izquierdo se encontraba cruzado por detrás del lateral y sin haber erupcionado por completo (figs. 1-A y J ). Las radiografías iniciales confirmaban la malposición dentaria y pérdida ósea con una proporción corona/raíz clínica desfavorable, afectando principalmente al sector anterior (fig. 1-B ). El plan de tratamiento se inició con la terapia periodontal utilizando técnicas quirúrgicas y no quirúrgicas. Se logró de esta manera el control de la infla- mación que resultó en retracción gingival y aumento de corona clínica (fig. 1-C ). A continuación se inició el tratamiento ortodóncico utilizando aparatología fija. Antes de la cementación de brackets, las coronas clínicas se redujeron (fig. 1-D). De este modo se logró una mejor proporción coronaraíz y fue más fácil colocar los brackets sin equivocarse en sentido vertical (fig. 1-E). Se extrajeron los incisivos laterales y se colocaron los caninos mesialmente. Al mismo tiempo se intruyeron los incisivos centrales y se logró la formación de una papila interdental (fig. 1-F). Como consecuencia del tratamiento periodontal combinado con la intrusión, se ganó soporte óseo en estos dientes con enfermedad periodontal avanzada (fig. 1-G). Una vez completado el tratamiento ortodóncico se logró un margen gingival engrosado, posicionado al nivel del límite amelocementario (fig. 1-H). El tratamiento se completó con cirugía estética periodontal con el objeto de corregir el agrandamiento gingival y dejar el área preparada para una futura restauración cosmética (fig 1-I). El enfoque combinado ortodóncicoperiodontal permitió corregir los problemas múltiples severos que tenía el paciente, mejorando significativamente el estado de su dentición y su pronóstico (fig. 1-J y K). En todo momento se utilizaron fuerzas extremadamente ligeras y el tiempo total de tratamiento fue de 4 años.

\section{Premisas ortodóncicas}

Antes de empezar el tratamiento ortodóncico, hay que mencionar una serie de normas que no se pueden olvidar si se quiere obtener un resultado exitoso. 

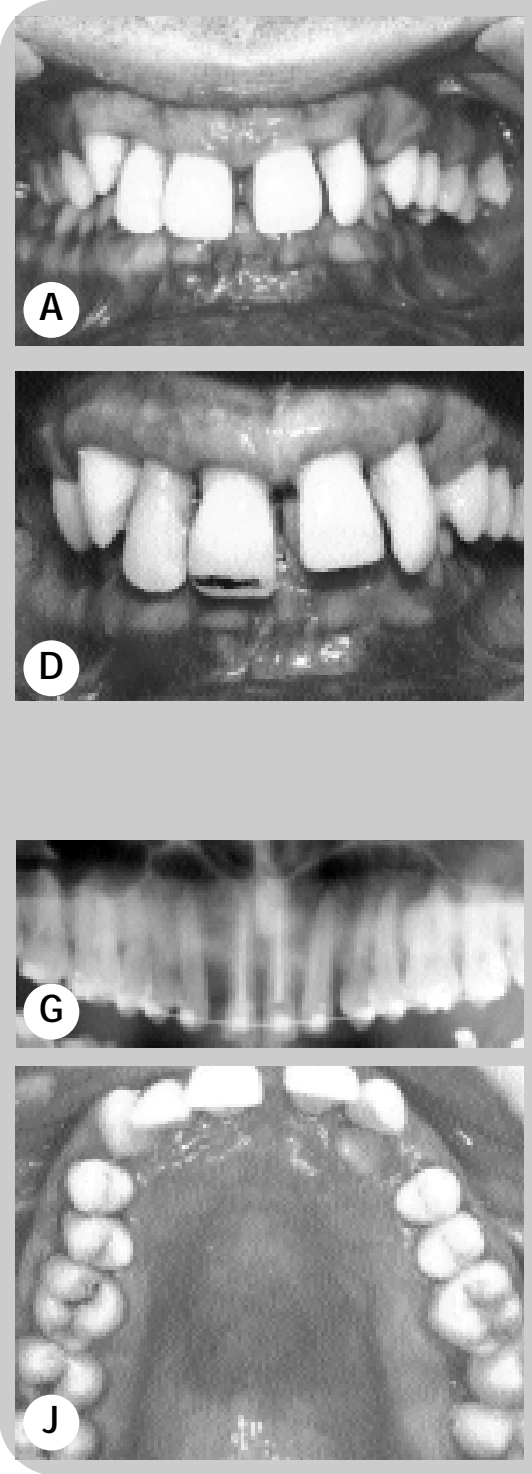

Debido a que los aparatos dificultan la limpieza, es imprescindible poner a los pacientes en un programa de higiene antes y durante el tratamiento. Como parte de este programa, deben hacerse revisiones por el periodoncista cada dos meses, que deben incluir profilaxis si se necesi$\tan ^{11}$. Los aparatos deben ser lo más simples posible procurando evitar la colocación de bandas en los molares
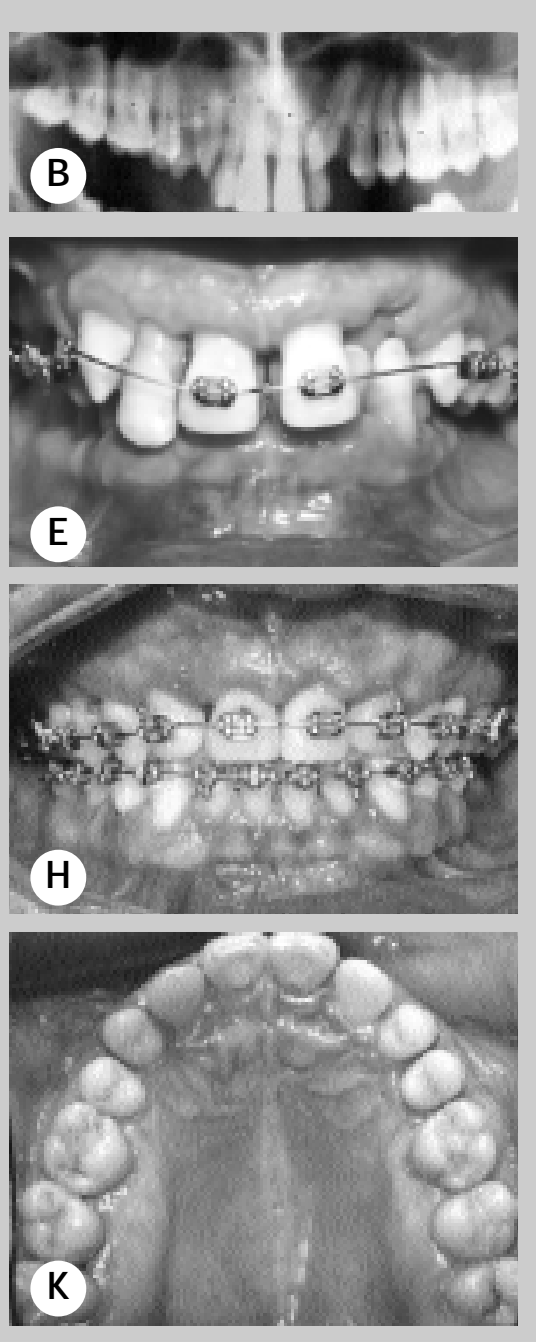

ya que éstas acumulan más bacterias en el surco gingival que los tubos cementados $^{12}$.

Como se puede ver, un factor muy importante a tener en cuenta a la hora de tratar adultos, es la elección de los aparatos ortodóncicos correctos. Se ha demostrado que los movimientos de vaiven favorecen la pérdida de soporte óseo, así que no es recomendable el tratamiento con
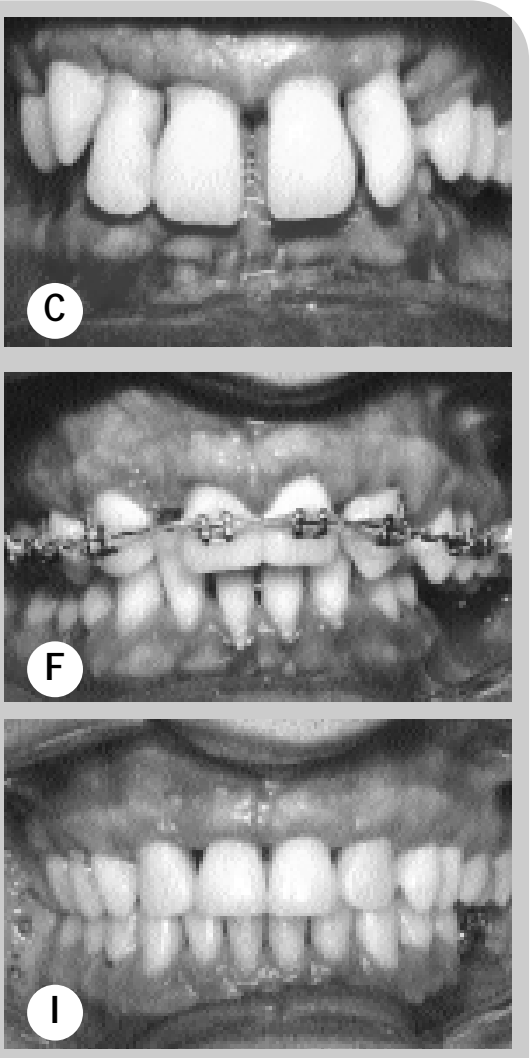

Figura 1. El tratamiento periodontal ha sido realizado por el Dr: José Borrás Amblar:

aparatología removible. Es mejor, por tanto, poner aparatología fija y tener cuidado con el uso de elásticos intermaxilares ${ }^{8}$. Por otro lado, esta aparatología provoca mayores reabsorciones radiculares, así que se deben utilizar los alambres más elásticos disponibles actualmente. Afortunadamente en los últimos años han aparecido alambres que son muy elásticos, incluso algunos se activan dependien- 
do de la temperatura y permiten un mayor control del movimiento desde las fases iniciales. Ejercen fuerzas muy ligeras y constantes, favorables a la fisiología del movimiento dental ${ }^{13}$. También se puede disminuir las fuerzas aplicadas utilizando aparatos que den la mayor distancia interbracket posible, liberando así en mayor medida el alambre ortodóncico entre los puntos de anclaje.

Con estas dos premisas, se pueden aplicar fuerzas tan ligeras como la presión capilar de 20 a $26 \mathrm{~g} / \mathrm{cm}^{2}$. Estas son las ideales ${ }^{14}$ ya que salvaguardan la integridad de los capilares, disminuyendo la hialinización y reabsorción, permitiendo la puesta en marcha de procesos de reparación cementaria. Si además se hacen las activaciones cada 6 u 8 semanas en vez de cada 3 o 4, la amplitud del movimiento puede ser mucho mayor. En resumen, se deben evitar las fuerzas pesadas, continuas y pendulares en todos los casos.

Después de haber valorado todas las premisas anteriores, se puede empezar el tratamiento ortodóncico para la rehabilitación, considerando los siguientes factores:

\section{Consideraciones que} afectan al diente, dimensión vertical, tejidos blandos y hueso alveolar

\section{Corona clínica/raíz clínica}

En los casos donde la enfermedad periodontal está muy avanzada, la relación corona/raíz clínica es desfavora- ble. El brazo de palanca externo es mucho mayor, favoreciendo la movilidad del diente. Aunque se le devuelva la salud periodontal y una buena función, el diente va a tener siempre peor pronóstico que si se intenta mejorar la relación corona clínica/raíz clínica. La forma de hacerlo, es desgastando el diente por su parte incisal, uno, dos o tres milímetros, según sea necesario y se pueda (sensibilidad, tamaño de cámara pulpar) y al margen del movimiento planeado, aunque sea intrusivo (fig. 1-E). Este procedimiento lo puede hacer el ortodoncista justo antes de empezar el tratamiento ortodóncico como parte del mismo, facilitando de ese modo la posición correcta de los brackets (fig. 1-F).

\section{Trauma oclusal}

Otros casos vienen combinados además con trauma oclusal que muchas veces les provocan movimientos de vaiven o «jiggling», sobre todo en los incisivos, cada vez que ocluyen. Los incisivos inferiores pegan con los superiores empujándolos hacia delante y favoreciendo que cada vez se vayan creando diastemas progresivos. Los pacientes reportan que en el último año se le han separado los incisivos muchísimo y es muchas veces el motivo de su consulta. Aquí hay que actuar más rápidamente y debe ser el primer especialista, después de los estudios pertinentes, quien realice el desgaste necesario para eliminar las interferencias que están creando el problema. En muchos casos será incluso necesario hacer una ferulización temporal con un alambre por lingual mientras se va haciendo el tratamiento periodontal, hasta que se empiece el ortodóncico.

\section{Dimensión vertical}

Otras muchas veces, el paciente presenta un colapso exagerado de la dimensión vertical, como consecuencia de las migraciones dentarias posteriores a la extracción de dientes vecinos. Los molares pueden adquirir posiciones anómalas estableciendo relaciones oclusales bloqueadas, que no permiten ni siquiera un pequeño movimiento o tampoco colocar un bracket. Si se coloca el bracket, este actúa como una prematuridad creando un trauma oclusal que genera movilidad excesiva del diente y pone en peligro su permanencia. En estos casos, se procura poner topes oclusales fijos o removibles en varios molares de ambos lados para repartir las fuerzas. Es necesario, sin embargo, evaluar el efecto que la apertura de la dimensión vertical pueda tener. Si esta es excesiva, habrá que desgastar la o las cúspides dentarias que estén interfiriendo, a pesar de que se trate de un procedimiento irreversible y agresivo para el diente. Estos desgastes no siguen las reglas mínimas de cualquier técnica de ajuste oclusal, donde las cúspides fundamentales o de soporte no deben tocarse. Se están tratando dientes afectados periodontalmente y en mala posición que hay que mover ortodóncicamente y si algo dificulta o impide este objetivo, es necesario facilitar el camino.

Se presenta con frecuencia una situación similar, cuando se deben tratar casos con sobremordida profunda y retroclinación de los incisivos inferiores. En estos casos, el movimiento ortodóncico se inicia intruyendo los incisivos superiores. Sin embargo, aún así es difícil evitar el choque excesivo de los brackets o bordes incisales inferiores con los antagonistas al 

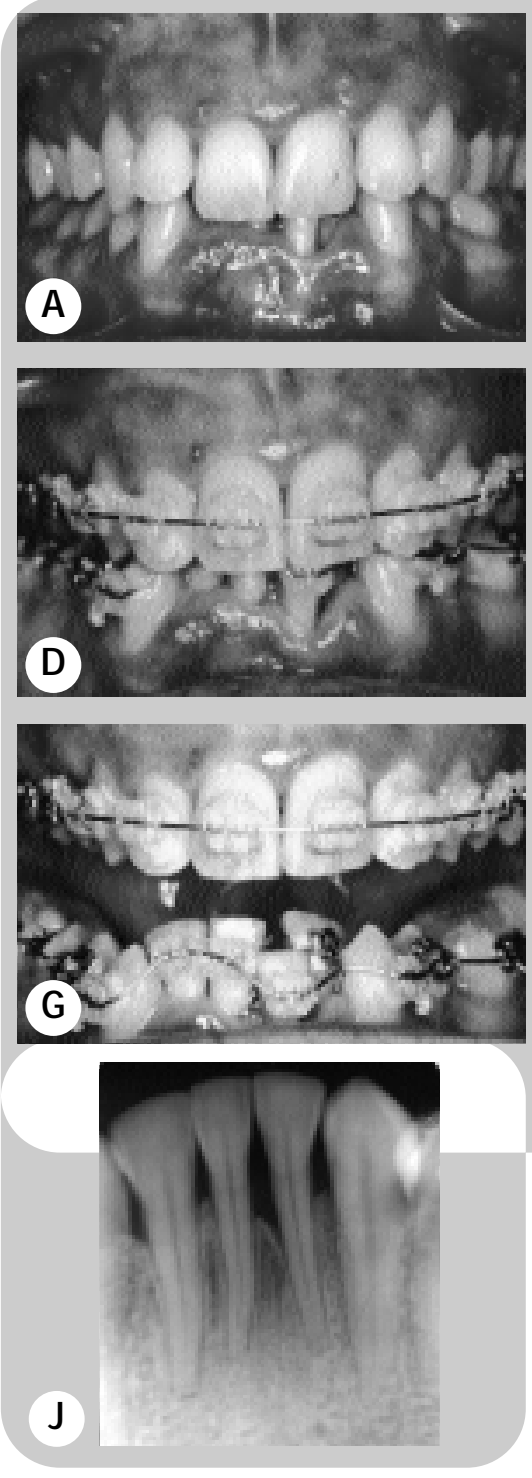

instalar la aparatología inferior. En general, el enfoque terapéutico es semejante al anteriormente descrito. Se aplican topes oclusales para destrabar la oclusión y se hacen desgastes selectivos para permitir el movimiento dentario. Es un concepto totalmente diferente a cuando se trata ortodóncicamente a niños en los que siempre se debe respetar la estructura dental. Como al realizar un remodelado inter-
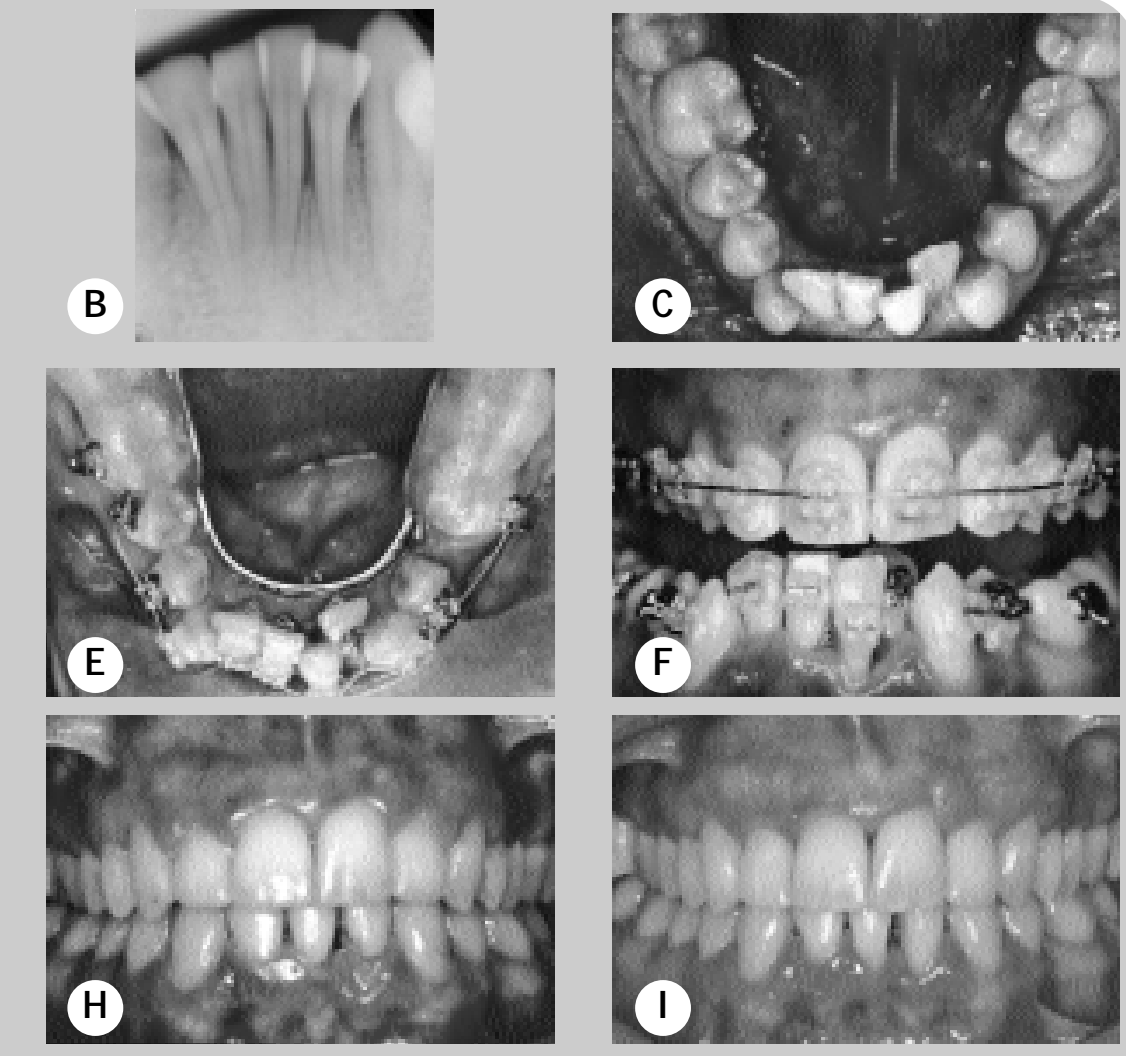

Figura 2. El tratamiento periodontal ha sido realizado por el Dr. Francisco Sada Garralda.

proximal o «stripping», aquí también hay que procurar ser lo más conservador posible con el desgaste.

Caso clínico 2. Paciente de sexo femenino de 32 años de edad, fumadora, con sobremordida y retroclinación con trauma directo de bordes incisales inferiores en el margen palatino. El sector anteroinferior presentaba apiñamiento severo y mostraba periodontalmente inflamación gingival con una recesión de $3 \mathrm{~mm}$ y una bolsa de $6 \mathrm{~mm}$ en el incisivo central izquierdo. Existía una pérdida ósea que afectaba severamente a este diente con signos de trauma oclusal presentes (figs. 2-A, B y C). La fase higiénica fue efectiva en controlar la inflamación gingival a excepción del sector anteroinferior donde la eliminación de placa se veía agravada por la malposición dentaria. Nueve meses después de haber empezado el tratamiento ortodóncico en el maxilar superior, se colocó la aparatología inferior ya que debido a la sobremordida había sido imposible hacerlo anteriormente (fig. 2-D). Con el objeto de permitir el movimiento dentario inferior sin causar interferencias, se colocó un tope oclusal extraible (fig. 2-E). Los brackets fueron colocados a diferente altura en los incisivos inferiores con el objeto de obtener el movimiento deseado en cada uno de 
estos dientes (fig. 2-F). El movimiento se inició colocando un arco de nivelación (016 Copper Ni-Ti, ORMCO, Glendora, CA ) (fig. 2-G). Durante el movimiento el incisivo central izquierdo, originalmente en linguoversión, fue desgastado, extruido y finalmente extraído para crear espacio y poder ubicar los demás incisivos (fig. 2-G). Al término del tratamiento ortodóncico se había reducido la sobremordida, corregido el apiñamiento, obtenido una relación interoclusal apropiada y mantenido la salud periodontal (fig. 2-H ). Dos años después del tratamiento, la paciente demuestra resultados muy estables y exitosos tanto en el aspecto ortodóncico como periodontal (fig. 2-I ). El incisivo lateral izquierdo y central derecho, fueron extruidos, como lo demuestra la comparación radiográfica de la ubicación de los ápices de estos dientes con los dientes contiguos. Para obtener dicha extrusión, el borde incisal de los mismos fue repetidamente desgastado. Radiográficamente se observa también la ganancia en altura de la cresta alveolar y la diferenciación de una nítida cortical alveolar. El defecto óseo marginal que existía originalmente, se ha reducido en tamaño y desplazado coronariamente (fig. 2-J ). El tiempo total de tratamiento fue de dos años.

\section{Tejidos blandos}

\section{Gingivitis o periodontitis}

Basado en el examen clínico de los tejidos blandos, se debe diagnosticar si existe o no una respuesta inflamatoria. De estar presente, es necesario diferenciar si las bolsas existentes son gingivales o periodontales. En orto- doncia es muy común encontrar bolsas gingivales debido a la respuesta inflamatoria antes y/o durante el tratamiento. Esto es cierto sobre todo en niños que no tienen hábitos correctos de higiene oral, pero también se puede encontrar en adultos. Sin embargo, se puede realizar el tratamiento ortodóncico en estas condiciones practicando profilaxis periódicas incluyendo instrucción en higiene oral. Es necesario además vigilar que no pasen a ser bolsas periodontales. En este caso, la respuesta inflamatoria migra apicalmente, se pierde inserción conectiva y hueso alveolar y se expone la raíz a la luz de la bolsa. Estos pacientes deben ser tratados periodontalmente antes de realizar el tratamiento ortodóncico ${ }^{15}$.

\section{Encía insertada}

Otro parámetro periodontal a considerar desde el punto de vista ortodóncico es la cantidad de encía insertada o queratinizada existente. Si bien es cierto que es posible mantener salud periodontal aún en su ausencia ${ }^{16-18}$, la encía insertada va a verse afectada por los diferentes movimientos dentarios ${ }^{19}$. Si se va a mover un diente con encía insertada insuficiente, dependerá de hacia donde se desplace, que se deba practicar una cirugía periodontal en base a colgajos o injertos antes del movimiento ortodóncico o no. La proclinación o intrusión de un diente reduce la encía insertada, por ende la cirugía se realizará antes del tratamiento ortodóncico. Por el contrario, la retroclinación y extrusión dental favorecen la formación de encía insertada, así que se postergará la cirugía ${ }^{20 *}$ (fig. 3).

Muchas de las recesiones gingiva- les, están condicionadas por una malposición dental que desplaza al diente fuera de la cortical ósea. El resultado del tratamiento periodontal será favorecido si el diente es recolocado ortodóncicamente antes de la cirugía.

\section{Papila interdental}

Otro de los tejidos blandos que se ve afectado en muchos tratamientos, es la papila interdental. Tanto en los tratamientos periodontales al eliminar la inflamación, como en los ortodóncicos al alinear ciertos dientes que están apiñados, se pierde y aparecen los antiestéticos triángulos negros ${ }^{21}$.

Tarnow y cols ${ }^{22}$, encontraron que si hay una distancia de $5 \mathrm{~mm}$ entre la cresta ósea y el punto de contacto interdental, hay una buena papila en el $100 \%$ de los casos, pero si hay $6 \mathrm{~mm}$ (tan sólo un mm más) la papila interdental sólo va a estar presente en un $56 \%$ de los casos y si son 7 los $\mathrm{mm}$ desciende a un $27 \%$

Esto explica porque en muchos tratamientos periodontales desaparece la papila. Antes de empezar el tratamiento los dientes han perdido hueso de soporte y la distancia entre éste y el punto de contacto es mayor a $5 \mathrm{~mm}$, pero al estar la encía inflamada se enmascara el problema. Cuando se hace el tratamiento periodontal y se elimina la inflamación, la encía se retrae y se reducen las papilas en gran parte de los casos.

Al estar los dientes apiñados, la relación de contacto se ubica más apicalmente. Al corregir el apiñamiento ortodóncicamente, la relación de contacto se ve desplazada hacia incisal y por lo tanto la distancia a la cresta alveolar aumenta. En un paciente adulto don- 

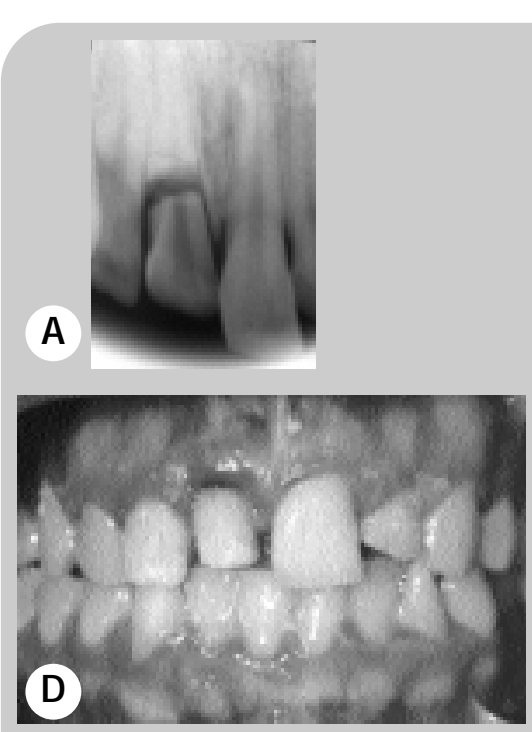
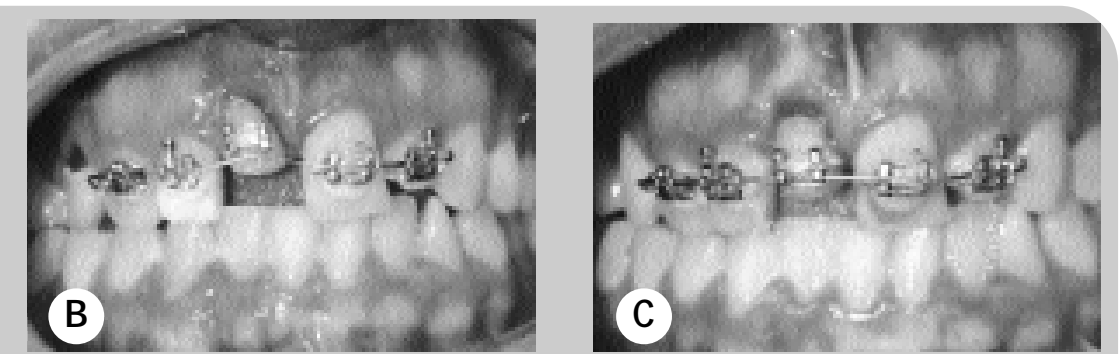

E

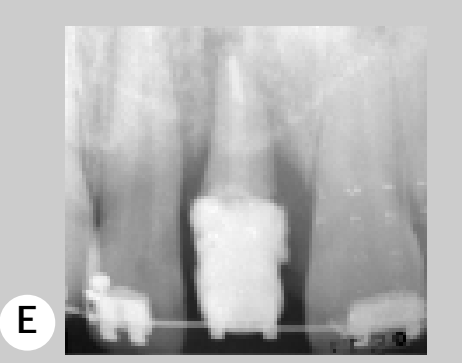

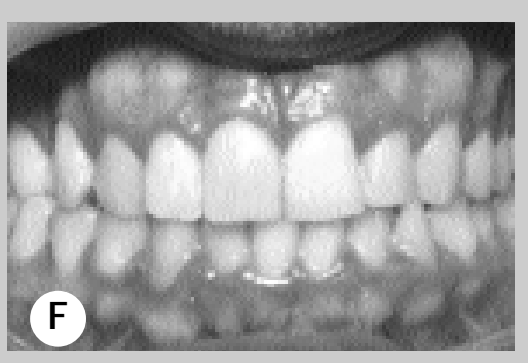

Figura 3. El tratamiento restaurador ha sido realizado por la Dra. Pilar Sada Garralda.

de ya ha habido pérdida ósea, si esa distancia es mayor de los $5 \mathrm{~mm}$ el tratamiento ortodóncico generará, por consiguiente, un triángulo negro.

Una posible solución a este problema, es el de desplazar apicalmente la relación de contacto utilizando el remodelado interproximal o «stripping $\aleph^{2,21}$ para reducir la distancia que la separa de la cresta ósea y así favorecer que la papila interdental ocupe la tronera correspondiente (fig. 4).

Otro enfoque posible, es el de producir ortodóncicamente la erupción forzada del diente involucrado. Al producir el movimiento eruptivo, los tejidos de soporte acompañan al diente en su desplazamiento coronario y por lo tanto la papila interdental también lo hace ${ }^{23}$. Ya que el hueso alveolar crece, la distancia clave de los $5 \mathrm{~mm}$ se ve reducida y la papila llena el espacio interdental. Vale la pena recalcar que con la erupción forzada se logra también un aumento vestibular de la encía insertada.
Caso clínico 3. Paciente de sexo masculino de 22 años que sufrió la fractura del incisivo central superior derecho a la altura de la mitad de la raíz y fracturas coronarias en varias piezas del sector anterior durante las fiestas de San Fermín de 1999 (fig. 3-A). La corona fue eliminada permitiendo observar la pérdida de gran parte de la tabla vestibular. Se confeccionó un muñón en resina compuesta, se realizó el tratamiento endodóncico de la raíz remanente y se reforzó con un perno. El muñón confeccionado permitió colocar un bracket y un arco seccional que se utilizó para lograr la erupción forzada de la raíz. Los brackets de anclaje se colocaron lo más nivelados posible, para no modificar la posición de esos dientes, aunque estuvieran en malposición (fig. 3-B). La extrusión del diente permitió el desplazamiento coronario del margen gingival (elongación) exponiendo el epitelio crevicular enrojecido que tiene potencial de queratinización (fig.
3-C). La extrusión de la raíz requirió seis meses para estar en condiciones de ser restaurado (fig. 3-D y E). Se realizó una restauración con resina compuesta que permitió obtener una relación muy aceptable del margen gingival con los dientes vecinos, reestableciendo las papilas interdentarias correspondientes (fig. 3-F). El tratamiento ha permitido mantener el diente y a la vez ganar hueso de soporte. La restauración está libre de oclusión y estabilizada a los dientes vecinos. En el futuro el diente deberá ser extraído para poder ser reemplazado con un implante unitario, pero será en mejores condiciones que cuando sufriera el accidente.

Caso clínico 4. Paciente de sexo masculino de 34 años con periodontitis crónica moderada. Presentaba apiñamiento en el sector anterior con los incisivos centrales superpuestos que desplazaba la relación de contacto apicalmente (fig. 4-A). Completado el 

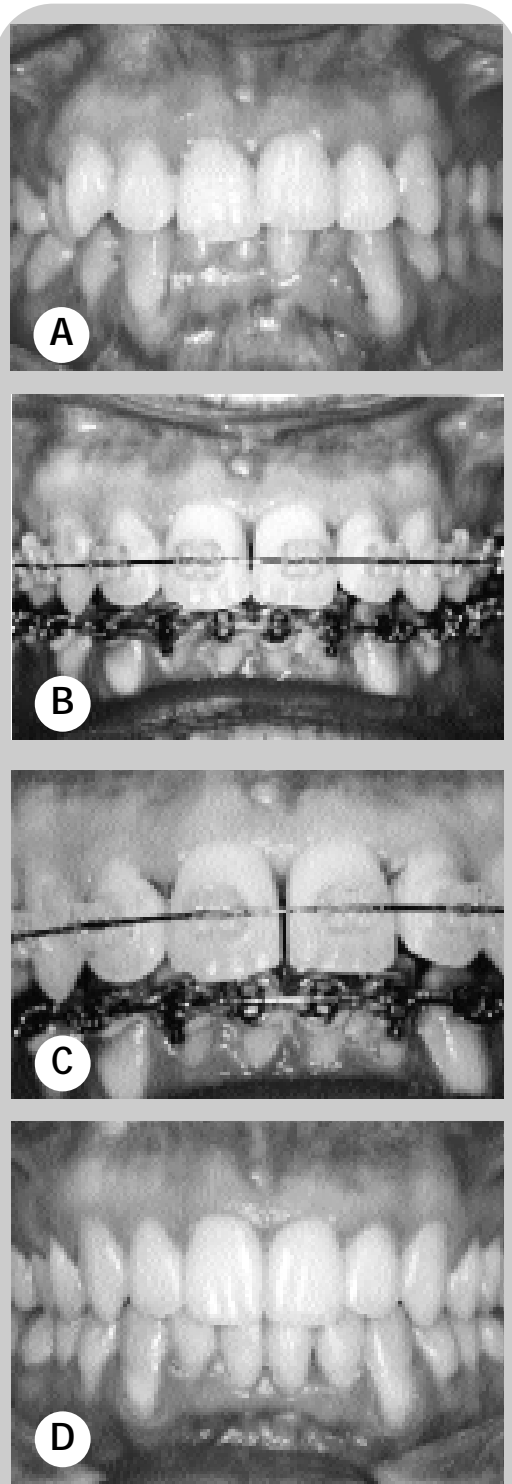

Figura 4. El tratamiento periodontal ha sido realizado por la Dra. $M^{a}$ Cruz Ferrer:

tratamiento periodontal se decidió realizar tratamiento ortodóncico. Al alinear los incisivos superiores la relación de contacto se desplazó incisalmente creando el típico triángulo negro (fig. 4-B). Esta complicación estética se solucionó practicando el remodelado interproximal (fig. 4-C).
Como resultado del mismo y de la reposición dentaria final, la distancia del punto de contacto a la cresta alveolar se vio reestablecida dentro de los 5 $\mathrm{mm}^{22}$ lográndose también el paralelismo de las raíces de los incisivos. Como consecuencia, las papilas ocupan totalmente el espacio interdentario mientras el contorno gingival se ha mantenido al nivel de los límites amelocementarios (fig. 4-D). El tiempo de tratamiento ha sido de 18 meses.

\section{Hueso alveolar}

El tratamiento que el paciente reciba tanto periodontal como ortodóncicamente, va a generar cambios en el hueso de soporte. Allí se observarán cambios en el remodelado óseo que lleven tanto a la reabsorción como a la neoformación del tejido alveolar.

\section{Desplazamiento dentario horizontal}

Se sabe que el movimiento de un diente conlleva consecuencias en el hueso de soporte. Cuando se mueve un diente, el hueso se reabsorbe en el lado de presión, mientras que se neoforma en el lado contrario o de tensión ${ }^{24}$. De este modo se puede mover el diente ortodóncicamente. Si el diente se mueve hacia una zona donde existe un defecto óseo, el defecto se va reduciendo conforme el diente va tomando su lugar. Al mismo tiempo, en el lugar previamente ocupado por el diente se formará hueso sin dejar defecto (fig. 5).

Esta respuesta al desplazamiento ortodóncico puede ser utilizada con fines clínicos para crear hueso en zonas donde no es suficiente, desplazando piezas dentarias vecinas a zonas con insuficientes rebordes ${ }^{25^{* *}}$. Esto se puede aplicar en cualquier área de la boca. Sin embargo es especialmente importante considerarlo cuando se desea colocar implantes en áreas maxilares posteriores. Allí su colocación puede verse imposibilitada porque la cresta ósea está muy reabsorbida o el seno maxilar muy neumatizado. Si se tiene la posibilidad de distalizar un premolar, al ir hacia atrás va desplazando el piso del seno hasta la altura de su ápice, pudiendo colocar el implante en el área de hueso neoformado que ha dejado el premolar. Esta opción es más conservadora y conlleva menos riesgos que la técnica de elevación de seno maxilar (fig. 6).

\section{Desplazamiento dentario vertical}

El hueso alveolar acompaña los movimientos del diente también en sentido vertical ${ }^{26,27}$. Si el diente se intruye, el hueso se desplaza apicalmente en su inserción al diente creando defectos intraalveolares. Estos pueden y deben ser tratados periodontalmente después del movimiento ortodóncico, con lo cual es posible aplicar técnicas regenerativas. Además se ha demostrado que si un diente se intruye en presencia de buena higiene oral y por ende salud gingival, es posible generar nueva formación de cemento con inserción de fibras colágenas ${ }^{28^{* *}}$. Si por el contrario el diente se extruye, el hueso alveolar se desplaza coronariamente con el diente. Así al tratar un diente muy afectado periodontalmente, es posible contemplar como parte del tratamiento periodontal su extrusión ortodóncica. Esto obligará a ir desgastando su borde incisal o cara oclusal con lo cual, 

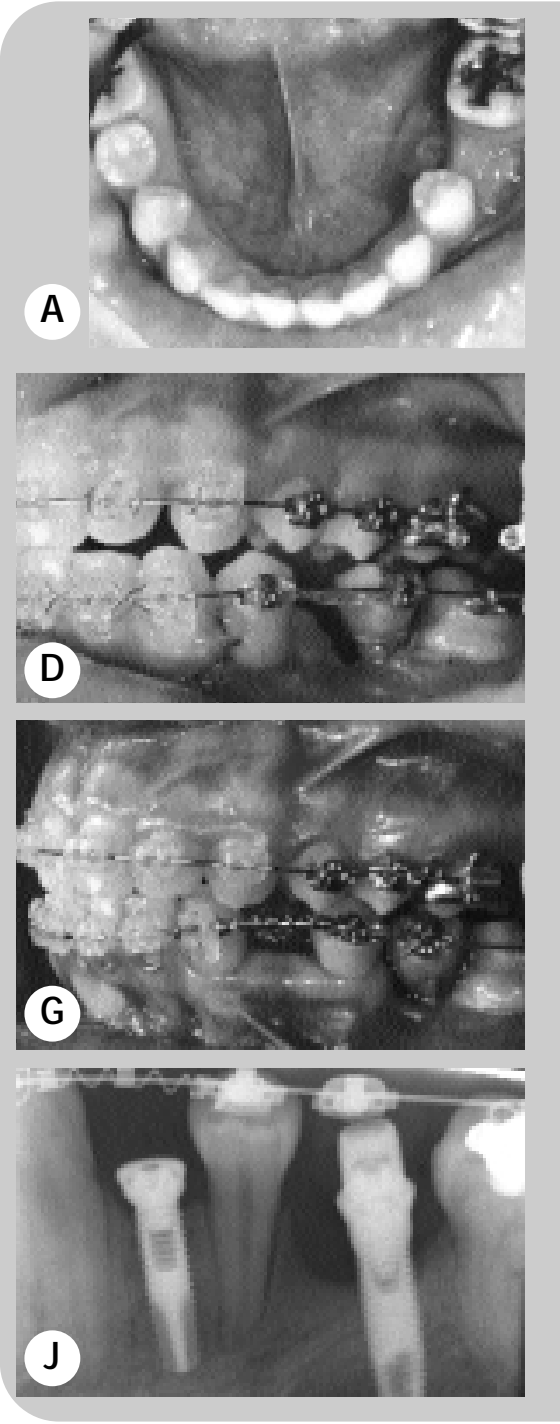

mejorará la proporción de la corona clínica con la raíz clínica. De esta manera se reduce también el defecto intraóseo y se mejora el pronóstico del diente ${ }^{29}$. Debido a la mejora que se da al hacer este procedimiento, dependiendo de la raíz clínica, se podrá decidir si se conserva el diente, se extrae o si es viable mantenerlo durante algunos años antes de poner un implante. Si no se puede salvar, en lugar de practicar su extracción inme-
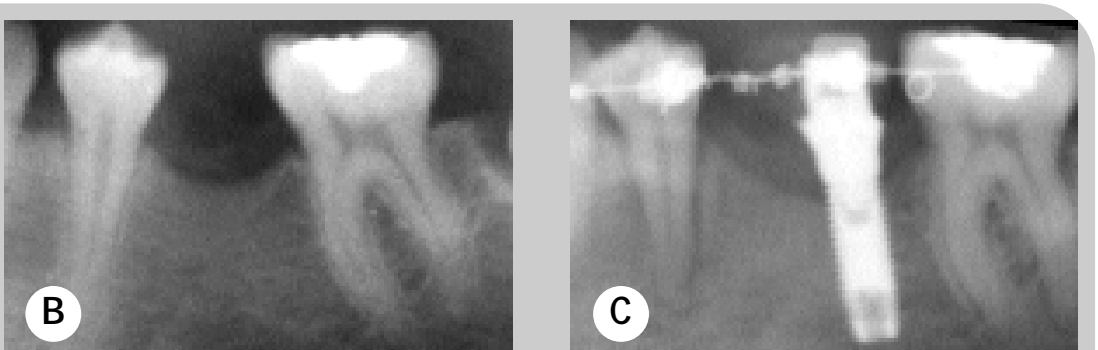

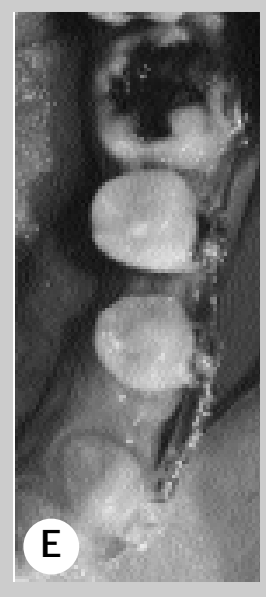

Figura 5. El tratamiento preventivo y restaurador ha sido realizado por el $D r$. Francisco Sada Garralda.
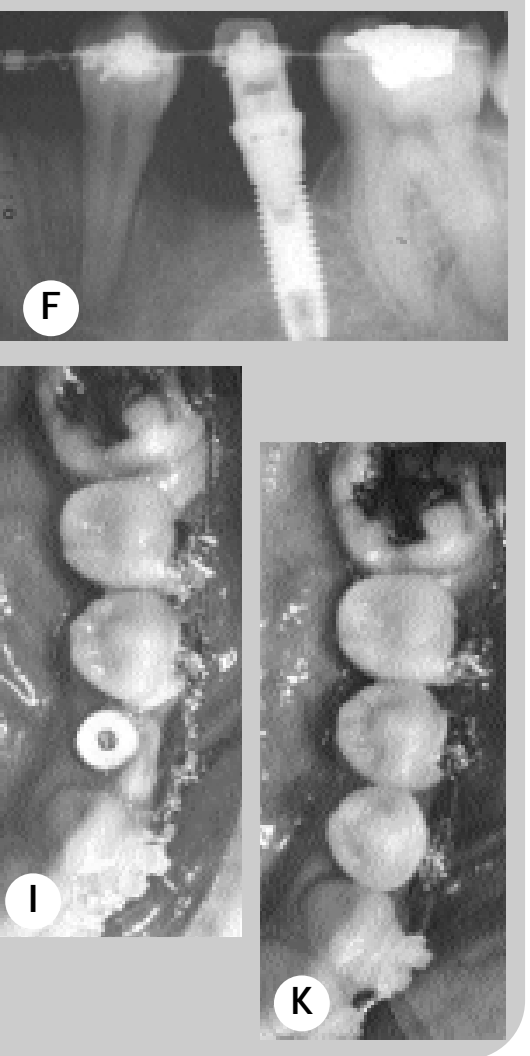

diata, es preferible extruirlo, e irlo cortando sucesivamente. A la hora de la extracción, la altura del hueso habrá aumentado, permitiendo la colocación de un implante o restaurando la altura del reborde en el área del póntico de una restauración fija (figs. 2 y 3 ).

La decisión de qué hacer va a depender de muchos factores y no solo del diente sino de cómo está el hueso, los dientes vecinos y la boca en general.
Caso clínico 5. Paciente de sexo femenino de 22 años periodontalmente sana, pero con maloclusión y áreas desdentadas. Mostraba espacio edéntulo entre el primer premolar y segundo molar (fig. 5-A). El examen radiográfico demostraba una altura ósea adecuada para la colocación de implantes (fig. 5-B). Sin embargo la brecha existente no era suficiente para la colocación de dos implantes debido a la migración de los dientes

RCOE, 2003, Vol 8, №6, 673-684 
vecinos. Se procedió a colocar un implante en posición del primer molar para ser utilizado como anclaje para el movimiento ortodóncico. El primer premolar fue mesializado para crear espacio y colocar un segundo implante (fig. 5-C). Al exponer el área, se determinó que el ancho del reborde óseo era insuficiente para recibir el implante. Se resolvió entonces, distalizar el primer premolar al lugar del segundo, creando reborde óseo para la colocación del implante en la zona del primero ${ }^{25 *}$ (fig. 5-D). Al ir distalizando el premolar se fue observando la diferencia en anchura y altura del reborde mesial y distal del primer premolar (figs. 5-E, F y G). La distalización se completó en 8 meses (figs. 5-G y H). El segundo implante fue colocado en el lugar del primer premolar nada más completar la distalización (figs. 5I y J). Es necesario destacar la diferencia en altura del reborde entre el área del implante inicialmente colocado y la creada como consecuencia del desplazamiento del primer premolar (fig. 5-J y G). El área ha sido restaurada con coronas temporales que sarán reemplazadas al completar el tratamiento ortodóncico (fig. 5-K).

Caso clínico 6. Paciente de sexo femenino de 40 años que presentaba periodontitis crónica moderada, maloclusión y pérdida de dientes con una prótesis fija en el sector superior
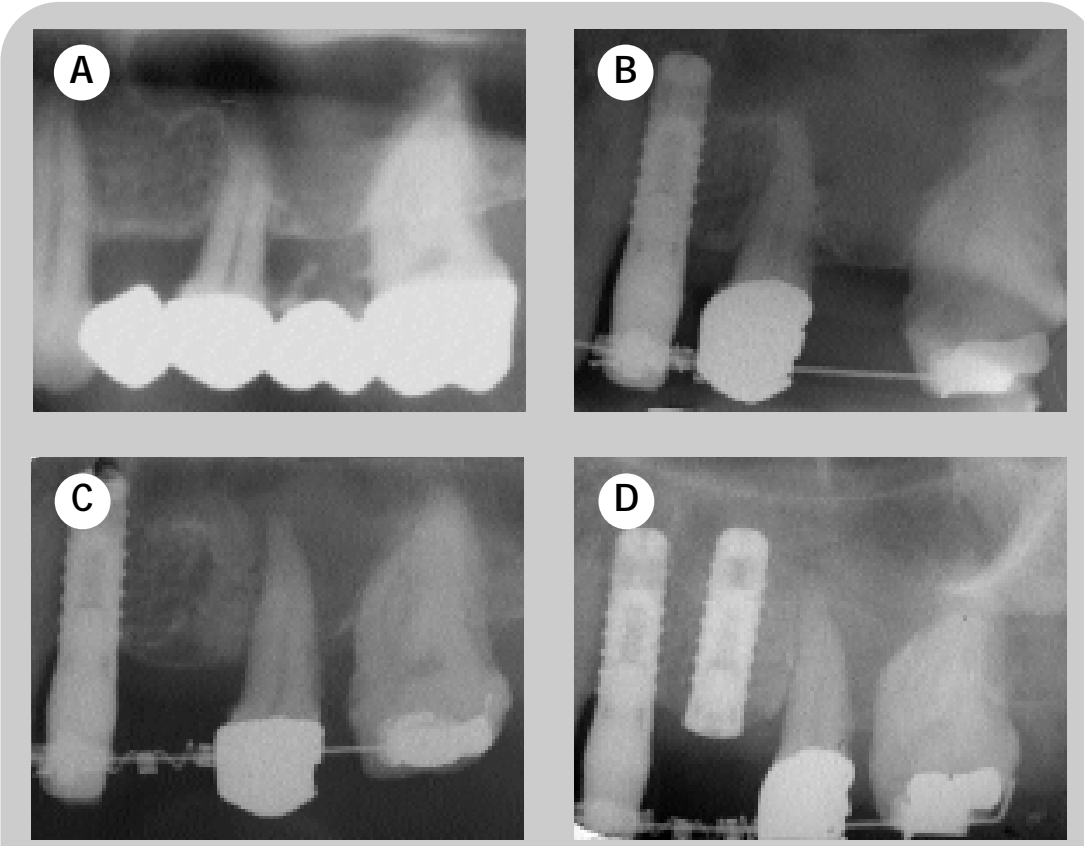

Figura 6. El tratamiento restaurador y periodontal ha sido realizado por el Dr. José Borrás Amblar.

izquierdo con pilares en el segundo premolar y segundo molar, que reemplazaba el primer molar y el primer premolar en extensión. El seno maxilar estaba ampliamente neumatizado, extendiéndose hasta el reborde en el área del primer molar y contactando las raíces de los dos dientes. Existía sin embargo, hueso trabecular por distal del canino (fig. 6-A). Se colocó un implante inmediatamente por distal del canino ya que el área del primer molar no admitía la colocación de un implante al menos que se realizara un levantamiento del seno maxilar. Orto- dóncicamente, el segundo premolar fue distalizado creando espacio y hueso por mesial del mismo, para colocar el segundo implante (fig. 6-B ). Después de siete meses de distalización, se ha formado hueso en mesial del premolar y su desplazamiento se ha completado (fig. 6-C). El segundo implante fue colocado diez meses después de comenzado el movimiento ortodóncico (fig. 6-D). El seno maxilar ejerció una gran oposición al movimiento, que fue más lento de lo normal a pesar de no haber hueso que se interpusiera. 


\section{Bibliografía recomendada}

Para profundizar en la lectura de este tema, el/los autor/es considera/an interesantes los artículos que aparecen señalados del siguiente modo: *de interés $* *$ de especial interés.

1. Higuchi K. Orthodontic applications of osseointegrated implants. Chicago: Quintessence Publishing Co, Inc, 2000

2. Sheridan J. The physiologic rationale for air-rotor stripping. J Clin Orthodont 1997;31: 609-12.

3. Echarri P. Procedimiento para el posicionamiento de brackets en ortodoncia lingual. Ortodoncia Clínica 1998;1:69-77.

4. Wiechmann D. Lingual orthodontics (Part 1): Laboratory procedure. J Orofac Orthop 1999;60:371-9.

5. Fillion D. Up-to-date lingual indirect bonding procedure. J Lingual Orthodont 1999;1:4-8.

6. Zachrisson BU. Implicaciones clínicas de las últimas investigaciones en ortodoncia-periodoncia. Semin Orthod 1996;2:4-12.

7. Yamaguchi K, Nanda RS, Kawata T. Effect of orthodontic forces on blood flow in human gingiva. Angle Orthodont 1991;61:193-203

8. Ericsson I, Thilander B, Linde J. The effect of orthodontic tilting movements on the periodontal tissues of infected and non-infected dentitions in dogs. $\mathrm{J}$ Clin Periodontol 1977:4:278-93.

9. Ericsson I. The combined effects of plaque and physical stress on periodontal tissues. J Clin Periodontol 1986;13:918-22

10. Thilander B. Orthodontic tooth movement in periodontal therapy. In : Lindhe $J$ ( ed ). Textbook of clinical periodontology. Second edition. Copenhagen: Munksgaard 1989: 563-70

11. Wagenberg BD. Periodontal preparation of the adult patient prior to orthodontics. Dent Clin N Amer 1988;32:457-80.

12. Alexander SA. Effects of orthodontic attachments on the gingival health of permanent second molars. Amer J Orthodont Dentofacial Orthop 1991;100:337-40.

13. Miura F, Mogi M, Ohura Y, Hamanaka H. The super-elastic Japanese alloy wire for use in orthodontics. Part III. Studies on the Japanese NITI alloy coil springs. Amer J Orthodont Dentofac Orthop 1988;24:89-96.
14. Schwarz AM. Tissues changes incidental to tooth movement. Int J Orthodont 1932;18:331-52

15. Lindhe J, Lang N, Karring T. Textbook of clinical periodontology. Second edition. Copenhagen: Munksgaard, 1989.

16. Dorfman H ,Kennedy J, Bird W. Longitudinal evaluation of free autogenous gingival grafts. A four-year report. J Periodontol 1982;53:349-57.

17. WennströmJ, Lindhe J. Role of attached gingiva for maintenance of periodontal health. Healing folowing excisional and grafting procedures in dogs. J Clin Periodontol 1983;10:206-11.

18. Wennström J, Lindhe J, Nyman S. Role of keratinized gingiva for gingival health. Clinical and histologic study of normal and regenerated gingival tissue in dogs. $\mathrm{J}$ Clin Periodontol 1981;8:311-28

19. Wennström J, Lindhe J, Sinclair F, el al. Some periodontal tissue reactions to orthodontic tooth movement in monkeys. J Clin Periodontol 1987;14:121-9.

20 **. WennströmJL. Consideraciones mucogingivales en el tratamiento ortodóncico.Semin Orthod 1996;2:46-54.

Artículo muy interesante en el que se describen los efectos que cada movimiento ortodóncico produce en el complejo mucogingival. Además, se explican las pautas de planificación del tratamiento en base a estos efectos, para hacer los movimientos ortodóncicos sin perjudicar los tejidos mucogingivales.

21. Kokich V. Estética: la conexión ortodonciaperiodoncia-odontología restauradora. Seminarios de Ortodoncia 1996;2:21-30.

22. Tarnow D, Magner A, Fletcher P. The effect of the distance from the contact point to the crest of bone on the presence or absence of the interproximal dental papilla. J Periodontol 1992;63:995-6.

23. Francischone $C$, Costa $C$, Francischone A, Ribeiro H, Silva R. Controlled orthodontic extrusion to create gingival papilla: A case report.Quintessence Int 2002;33:561-5.

24. Reitan K. The initial tissue reaction incident to orthodontic tooth movement as related to the influence of funtion. Acta Odont Scand 1951;9:(supplement 6)1-239.

$25 * *$. Thilander B. Bolsas infraoseas y pérdida de altura de hueso alveolar en relación con el tratamiento ortodóncico. Semin Orthod 1996;2:55-61.

Demostró que un diente con soporte periodontal normal se puede mover ortodóncicamente hacia na zona de altura ósea reducida manteniendo la altura del aparato de soporte, es decir, el nivel de inserción del tejido conectivo y el hueso alveolar.

26. Berglundh T, Marinello C, Lindhe J, et al. Periodontal tissue reactions to orthodontic extrusion. J Clin Periodontol 1991;18:330-6.

27. Salama H, Salama M. The role of orthodontic extrusive remodeling in the enhancement of soft and hard tissue profiles prior to implant placement: A sistematic approach to the management of extraction site defects. J Periodont Rest Dent 1993;13:313-33.

28**. Melsen B, Agerbaek N, Eriksen J, Terp S. New attachment through periodontal treatment and orthodontic intrusion. Am J Orthod Dentofacial Orthop 1988;94:104-16.

Hicieron un estudio para ver la reacción de los tejidos a la intrusión de dientes con un periodonto reducido y posteriormente evaluar la influencia de la higiene oral en esta reacción. Los análisis histológicos mostraron que después del procedimiento quirúrgico periodontal manteniendo una buena higiene oral se obtenía nueva formación de cemento y fibras colágenas, pero si además se combinaba con la intrusión de los dientes, los resultados eran todavía mejores. La combinación de tratamiento periodontal con intrusión dental puede mejorar el estado periodontal si el sistema biomecánico y la higiene oral se tienen bajo control.

29. Everett F, Baer P. A preliminary report on the treatment of the osseous defect in periodontosis. J Periodontol 1964;35:429-35. 